\title{
Effect of Arsenic in germination, growth and biochemistry of Rice (Oryza sativa)
}

\author{
Priyanka Biswas, Syed Yakub Ali, Pulak Kumar Patra*
}

Department of Environmental Studies, Visva-Bharati, Santiniketan, West Bengal, India

\begin{abstract}
Arsenic is a highly toxic metalloid element and occurs in many minerals, usually in conjunction with sulfur and metals, and also as a pure elemental crystal. Arsenic poisoning from naturally occurring arsenic compounds in drinking water remains a problem in many parts of the world. Arsenic contaminated water is also used in the agricultural field for irrigation purpose. The influence of 0 , 1,2 and $4 \mathrm{mg} / \mathrm{l}$ sodium arsenite on germination, seedling growth and biochemistry of two varieties of Rice (Oryza sativa), Nayanmani and Satabdi was studied under controlled conditions. After 3 weeks the various parameters (percentage of seed germination, root and shoot length, dry biomass, chlorophyll, peroxidase, protein and ascorbic acid content) were estimated following standard procedures. It was observed that the root and shoot length, germination percentage, dry biomass, protein content, chlorophyll, ascorbic acid content and peroxidase activity decreased significantly with increasing exposure to arsenic in both the plant varieties. The study shows that arsenic is toxic to both rice varieties and affects adversely the normal rate of germination and growth through alteration in the plant biochemistry.
\end{abstract}

Keywords- Arsenic, Biochemistry, Seed germination, Seedling growth, Vigor index.

\section{INTRODUCTION}

Arsenic is a toxic pollutant in the environment. Thousands of people are suffering from it in many countries all over the worlds including India and Bangladesh. The arsenic contamination in the affected regions is mostly through the presence of high concentration of arsenic in groundwater. The arsenic contaminated ground water in those areas is used not only used for drinking and domestic use purposes, but also for irrigating crops. The arsenic from both soils and irrigation water is accumulating in vegetables and rice grains during cultivation. Several crops such as rice, wheat, potato, sweet potato, carrot, radish, onion, garlic, cauliflower, broccoli, cabbage, celery, chinese cabbage, lettuce, ginger, tomato, cucumber, eggplant, spinach, bamboo shoot, snake gourd, ghotkal, taro, green papaya, elephant foot, turmeric, beans and chili have been reported to accumulate arsenic in their edible parts like leaves, fruits and grain through the irrigation of arsenic-contaminated water [1-6].

Rice is the main crop in Eastern India and Bangladesh where arsenic menace is the most prominent. In Bangladesh, rice cultivation covers about $75 \%$ of the total crop field area and $83 \%$ of the irrigated area. A large number of shallow tube well (STW) and deep tube well (DTW) have been installed both in India and Bangladesh to irrigate about million hectors of crop land. This contributes significantly to increase in the food grain production of the country [7]. However, long-term use of arsenic contaminated groundwater for irrigation has resulted in elevated soil arsenic levels in agricultural lands [8,9]. The arsenic from both soils and water find their way to the plant parts and ultimately to human body through food chain. Rice grain has been reported to accumulate arsenic up to $2.0 \mathrm{mg} / \mathrm{kg}$ in grain $[10,11]$ and up to $92 \mathrm{mg} / \mathrm{kg}$ in straw. According to WHO recommendation the permissible limit of Arsenic in rice is $1 \mathrm{mg} / \mathrm{kg}$ [12].

Presence of high level of arsenic in rice or any plants can hamper the normal growth and development like inhibition of seed germination, decrease in plant height, reduction in root growth, lower fruit and grain yield, and sometimes also leads to death [12]. As a result, the crop yields and productivity is reduced drastically due to the arsenic phytotoxicity.

Plants normally accumulate arsenic in trivalent (AsIII) and pentavalent (AsIV) forms, which interfere with different metabolic pathways in cells like interaction with sulfohydryl groups and replacement of phosphate from ATP. Heavy metals including metalloid As stimulate the formation of free radicals and reactive oxygen species which lead to oxidative stress $[13,14]$. Requejo and Tena, 2005[15] reported the effect of arsenic exposure on maize (Zea mays L.) root proteome and concluded that the induction of oxidative stress is the main process underlying arsenic toxicity in plants. Plants respond to oxidative stress by increasing the production of antioxidant enzymes such as 
superoxide dismutase (SOD), ascorbate peroxidase (APX) or peroxidase (POD).

The importance of seed germination in plant growth is widely recognized and its study has been used as a model for investigating toxicity of different element [12]. The present study reports the results of a laboratory investigation on the effect of arsenic on the germination of rice (Oryza sativa) and its effect on the physiology and biochemistry of germinated seedlings.

\section{MATERIALS AND METHODS}

\subsection{Experimental Design}

About three hundred healthy seeds of two varieties of 'Amon' rice (Ozyza sativa) i.e. Satabdi and Nayanmani were collected for the study. The seeds were soaked in distilled water for $24 \mathrm{hrs}$ in the dark at room temperature $\left(23 \pm 2^{\circ} \mathrm{C}\right)$. Twenty-five seeds were placed in each of three sets of four petridishes, covered by lid and incubate at $25^{\circ}$ C. The petridishes contained filter paper moistened from below with sterilized cotton pads treated with four different concentrations i.e., 0, 1, 2 and $4 \mathrm{mg} / \mathrm{l}$ of Sodium Arsenite $\left(\mathrm{NaAsO}_{2}\right)$. Thus, for each arsenic concentration including the $0-\mathrm{mg} / \mathrm{l}$ control, three replicates were made. The selected test seeds in each petri dish were treated with $10 \mathrm{ml}$ of the aqueous $\mathrm{NaAsO}_{2}$ solutions prepared from a stock solution. Distilled water was used for treating the control seedlings. When germination was completed, the percentage (\%) of germination was calculated for each concentration. After 3 weeks, when the seedlings have matures, they were removed from the Petri dishes for further analysis. The growth parameters (the shoot and root length) were measured and recorded. The biochemical parameters (chlorophyll content, ascorbic acid content, protein and peroxidase) were estimated following standard procedure.

\subsection{Germination and Growth measurement}

Germination was completed within three to four days. The number of germinated seeds in each petri dish was counted, and the percentage $(\%)$ of germination was calculated. The mean values were calculated from the results of the three replicates. After three weeks, total test seedlings were taken out and washed gently with water to remove non-plant particles adhering to them. The length of root and shoot of the best-grown plant from each Petri dish was measured separately. The Vigor index of growth was calculated according to the equation of Abdul-Baki and Anderson [16]. Vigor index $=($ Root length + Shoot length $) \times$ Germination percentage

The biomass was determined by determining the fresh and dry weights. One best-grown seedling from each petri dish was selected and weighed to get the fresh weight. The seedlings were wrapped in labeled blotting paper, oven dried at $80^{\circ} \mathrm{C}$ for $24 \mathrm{hrs}$, and the dry weight was then recorded.

\subsection{Biochemical analysis}

Biochemical parameters such as the content of Chlorophyll, ascorbic acid, peroxidase and protein in the seedlings were measured as follows. Extracts were prepared from the required number of plants from individual Petri dishes.

For estimation of chlorophyll, the plant materials were extracted in $80 \%$ acetone and the solution absorbance at 645 and $663 \mathrm{~nm}$ was recorded [17]. The amounts of the chlorophyll-a, chlorophyll-b and total chlorophyll as mg/g fresh plant weight were estimated by following equations.

mg Chlorophyll a/g tissue $=\left[12.7\left(\mathrm{~A}_{663}\right)-2.69\left(\mathrm{~A}_{645}\right)\right] \mathrm{x}$ $\mathrm{V} /(1000 \mathrm{xW})$

mg Chlorophyll b/g tissue $=\left[22.9\left(\mathrm{~A}_{663}\right)-4.68\left(\mathrm{~A}_{645}\right)\right] \mathrm{x}$ $\mathrm{V} /(1000 \mathrm{xW})$

$\mathrm{mg}$ Total Chlorophyll/g tissue $=\left[20.2\left(\mathrm{~A}_{645}\right)+8.02\left(\mathrm{~A}_{663}\right)\right] \mathrm{x}$ $\mathrm{V} /(1000 \mathrm{xW})$

where , $\mathrm{A}=$ absorbance at specific wavelengths, $\mathrm{V}=$ final volume of Chlorophyll extract in $80 \%$ acetone, and $\mathrm{W}=$ fresh weight of tissue.

Ascorbic acid was estimated by titrimetric method from the plant material extracted with $4 \%$ oxalic acid [18].

Peroxidase (POD) activity was estimated at $4{ }^{0} \mathrm{C}$ with guaiacol by spectrophotometry [18]. In the presence of $\mathrm{H}_{2} \mathrm{O}_{2}$, POD catalyzes the transformation of guaiacol to tetraguaiacol. This reaction can be recorded at $470 \mathrm{~nm}$.

Protein was estimated by Lowry method [19] using bovine serum albumin as a standard.

\subsection{Statistical Analysis}

Statistical analysis was done by using SPSS 20. Duncun's multiple range test (DMRT) was used for comparisons of the treatment at the $5 \%$ level of probability.

\section{RESULTS AND DISCUSSION}

\subsection{Effect of Arsenic on germination}

Seed germination is one of the most sensitive processes to metal pollution and hence is an important consideration while studying effects of heavy metals on seedling growth [20]. We studied the effects of arsenic on seed germination and found that arsenic inhibited the germination of both varieties of tested plants. The inhibition increased with increased arsenic concentration. The germination of percentage of $4 \mathrm{mg} / \mathrm{l}$ treated Satabdi plants was inhibited about $13.3 \%$ and Nayanmani plants was inhibited about $4 \%$ 
in comparison to the control plants (Fig.1). Similar result have also been by some previous workers. [12, 13].

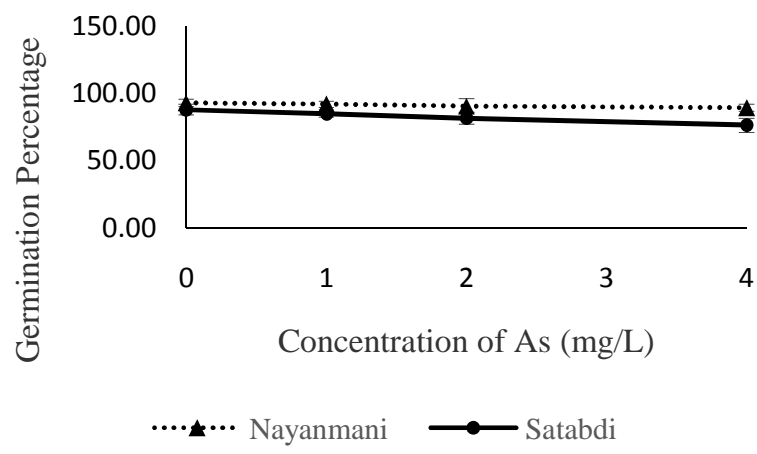

Fig. 1: Effect of arsenic on seed germination ( Error bars represent $\pm S E$ ).

3.2. Effect of arsenic on Root and Shoot length

Arsenic inhibited the growth of the seedlings as evidenced from the measurement of their root and shoot lengths. The root and shoot length of both Satabdi and Nayanmani were significantly decreased the compared to the control. The shoot length of $4 \mathrm{mg} / \mathrm{l}$ treated Satabdi plants was inhibited about $32.8 \%$ and Nayanmani plants was inhibited about $60.2 \%$ in comparison to the control (Fig.2). The root length of $4 \mathrm{mg} / \mathrm{l}$ treated Satabdi plants was inhibited about $65.4 \%$ and Nayanmani plants was inhibited about $65.1 \%$ by the compared to the control (Fig.3). Several previous studies showed that plants were inhibited by arsenic in a dosedependent manner [13,14,21]. Plants accumulate arsenic in trivalent (AsIII) and pentavalent (AsIV) forms. These forms interfere with phosphate in various metabolic pathways, and interact with sulfhydryl groups on proteins. Roots are found to be more affected than shoots because they contact with arsenic compounds at first than shoots.

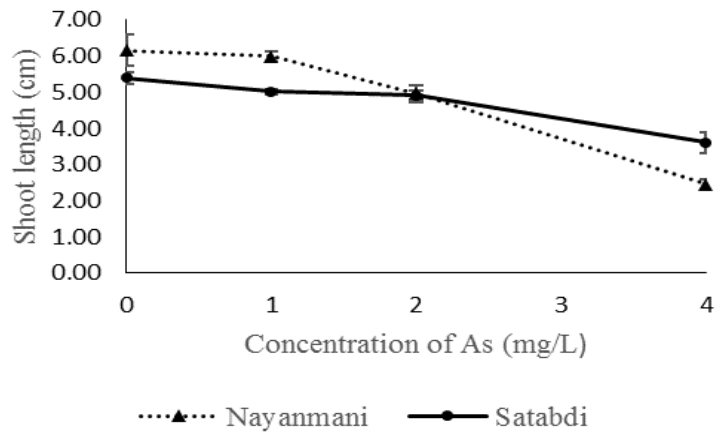

Fig. 2: Effect of arsenic on shoot length (Error bars represent $\pm S E$ )

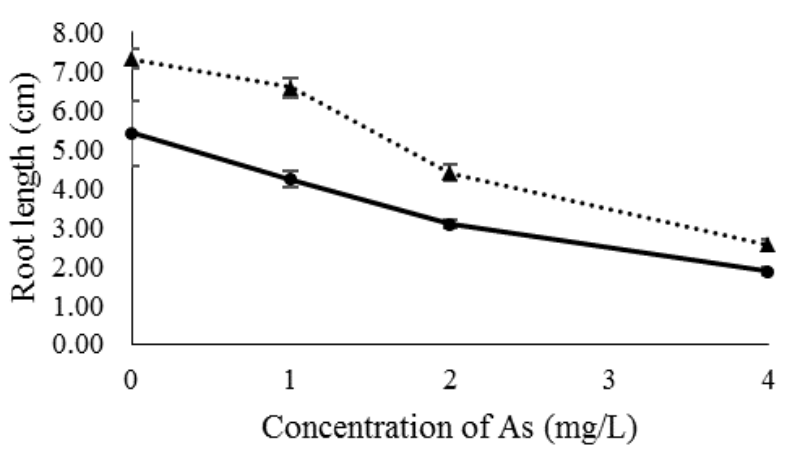

....... Nayanmani $\longrightarrow$ Satabdi

Fig. 3: Effect of arsenic on Root length

(Error bars represent $\pm S E$ ).

\subsubsection{Vigor index}

Since the vigor index of growth is a factor of root length, shoot length and germination percentage, it also showed a direct reduction when the concentration of sodium arsenite was increased (Fig.4).

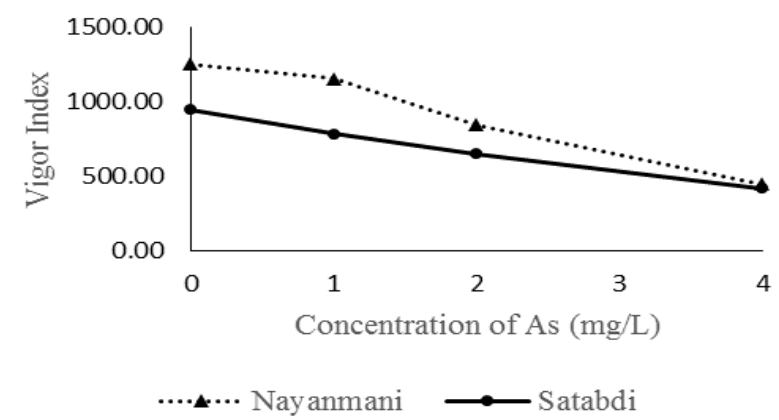

Fig. 4: Effect of arsenic on Vigor Index

\subsection{Effect of Arsenic on Dry biomass}

Dry biomass of $4 \mathrm{mg} / \mathrm{l}$ treated Satabdi plants was significantly decreased about $75 \%$ and Nayanmani was about $67 \%$ by compared to the control of Satabdi and Nayanmani respectively (Fig.5). On exposure to different concentrations of arsenic for three weeks, rice plants showed prominent effect on the whole plant biomass. Biomass is generally used in studies of metal resistance to plants. The arsenic treatment resulted in symptoms of phytotoxicity and considerable inhibition of growth and reduced biomass of that species of rice plants. 


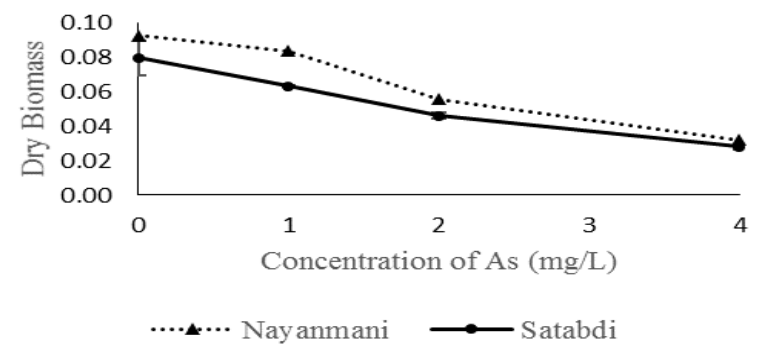

Fig. 5: Effect of arsenic on Dry Biomass

(Error bars represent $\pm S E$ )

3.4. Effect of Arsenic on Chlorophyll content Chlorophyll content was decreased by Arsenic treatment, because when heavy metal was entered in leaves then some parts were accumulated excessively and combined with $-\mathrm{SH}$ base of protein and then destroyed the structure and function of chloroplast. The decreasing tendency of chlorophyll was found in our present study for As treated seedlings in Nayanmani cultivar. Total Chlorophyll, Chlorophyll-a and Chlorophyll-b, decreased with increasing concentrations of arsenic accompanied by the pale green coloration of the leaves. At $4 \mathrm{mg} / \mathrm{L}$ sodium arsenite concentration of Nayanmani, chlorophyll-a and chlorophyll-b were reduced by $41.8 \%$ and $44.45 \%$, respectively, from the control concentration, whereas the total chlorophyll content decreased by $42.36 \%$ (Fig.6,7,8) But the effect of arsenic toxicity is not apparent in Satabdi cultivar. According to Miteva and Merakchiyska, 2002[22], higher arsenic concentrations can resulted alteration of the chloroplast shape, manifested in its rounding and shortening of the longitudinal axis of plant cell and partial destruction along with the changes in the accumulation to the decrease of chlorophyll contents in rice leaf

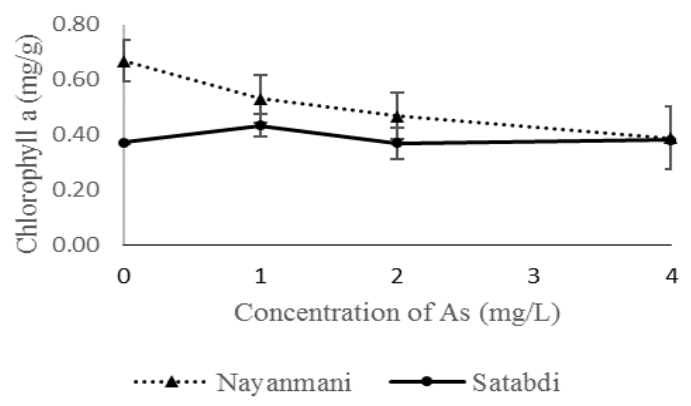

Fig 6: Effect of arsenic on Chlorophyll a (Error bars represent $\pm S E$ )

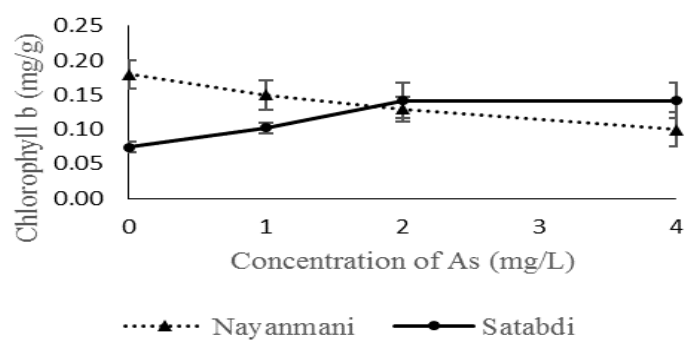

Fig7: Effect of arsenic on Chlorophyll b (Error bars represent $\pm S E$ )

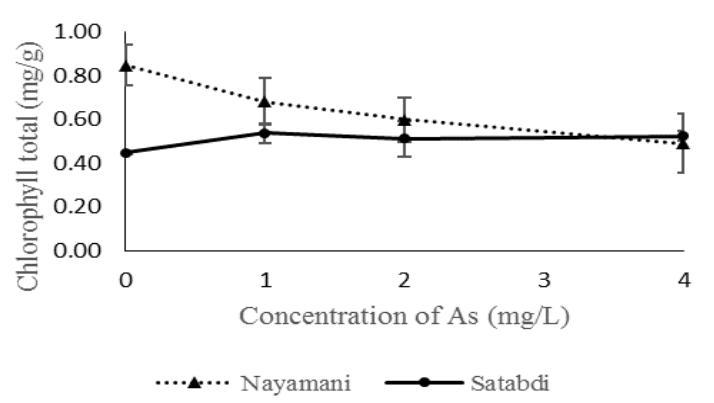

Fig8: Effect of arsenic on Chlorophyll total (Error bars represent $\pm S E$ )

\subsection{Effect of Arsenic on Peroxidase}

Generation of free radicals and reactive oxygen species are stimulated in the presence of trace elements (TEs) which can damage cell membranes, nucleic acids and chloroplast pigments $[23,24,25]$. To mitigate and repair the damage originated by ROS, plants release various antioxidant enzyme such as catalase (CAT), peroxidases (POD) and superoxide dismutases (SOD), and non-enzymic scavengers, e.g. glutathione, carotenoids and ascorbate [26]. In the present study, significant reduction in peroxidase activity was observed with increasing doses of arsenic. Mean peroxidase activity recorded was least in control i.e. $165.88 \mathrm{OD} / \mathrm{g}$ fresh weight/min in Satabdi and 165.89 OD/g fresh weight $/ \mathrm{min}$ in Nayanmani. For the $4 \mathrm{mg} / \mathrm{l}$ arsenic exposure, it was $23.69 \mathrm{OD} / \mathrm{g}$ fresh weight/min in Satabdi and about $36.19 \mathrm{OD} / \mathrm{g}$ fresh weight $/ \mathrm{min}$ in Nayanmani (Fig.9). According to Pandey and Sharma, 2002[26], peroxidase are heam $(\mathrm{Fe})$ containing enzyme and TEs inhibit Fe uptake, so, the peroxidase activity may have decreased. Another study by Schützendübel and Polle, 2002[27] reported that peroxidase activity can be decreased by the substitution of TEs instead of essential ions in the enzyme structure or because of increase in ROS accumulation which effects the plant signal transduction pathways. 


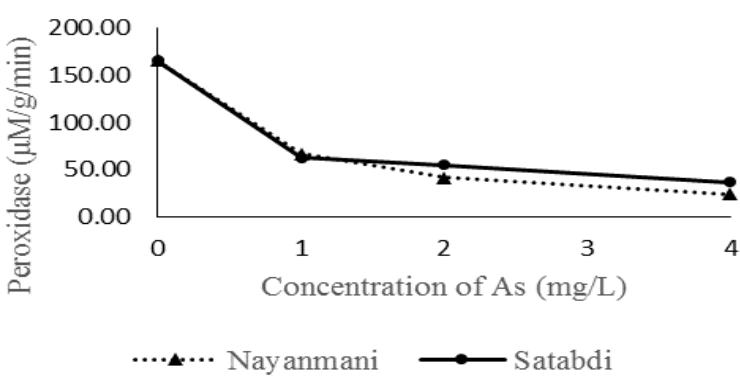

Fig.9: Effect of arsenic on Peroxidase

\subsection{Effects of Arsenic on Protein}

Protein content significantly decreased with exposure to arsenic in both the cultivars. At $4 \mathrm{mg} / \mathrm{l}$ arsenic concentration of the protein content was reduced by $48.56 \%$ and $68.34 \%$ of the control value in Satabdi, and Nayanmani respectively (Fig.10). Protein contents decrease may be due to more oxidative injury by TEs [28,29].

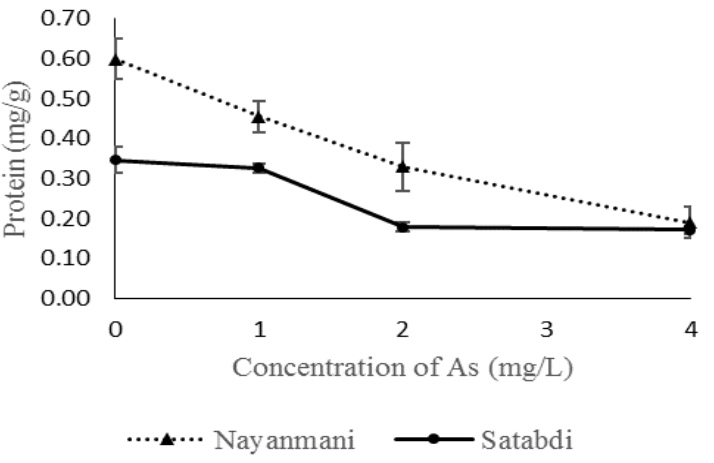

Fig.10: Effect of arsenic on Protein (Error bars represent $\pm S E$ ).

\subsection{Effect of Arsenic on Ascorbic acid}

Ascorbic acid is a primary cellular antioxidant and also functions as a secondary antioxidant because it represents a cellular reservoir to regenerate $\alpha$ tocopherol, which scavenges lipid peroxide radicals[30]. It plays an important role against physiological stress. In this study it was found that the ascorbic acid content significantly decreased under arsenic treatment as compared to the control (Fig.11). At $4 \mathrm{mg} / 1$ arsenic concentration of Satabdi and Nayanmani, the ascorbic acid was reduced about $60 \%$ by the compare to the control plants.

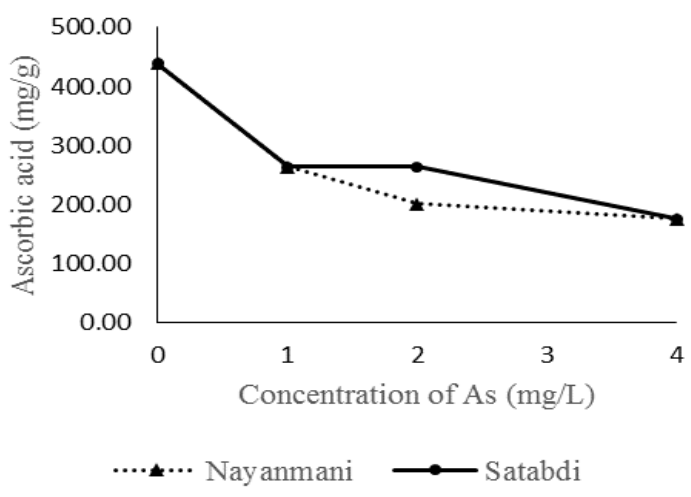

Fig.11: Effect of arsenic on Ascorbic Acid

\section{CONCLUSION}

The present study demonstrates that that arsenic inhibits the germination and seedling growth in rice cultivars. Root and shoot length can be used as a good indicator for arsenic toxicity. Arsenic toxicity also affected the chlorophyll, protein and ascorbic acid content in the seedlings and reduced the peroxidase activity. There was considerable difference in arsenic tolerance between the two studied rice varieties. Nayanmani showed a higher tolerance to arsenic compared to Satabdi. The rate of decrease in peroxidase activity and ascorbic acid content was highest in lowest $(1 \mathrm{mg} / \mathrm{l})$ As concentration, where after it continues to decrease slowly. Moreover, the tolerant variety Nayanmani showed relatively more reduction. From this study, it is clear that the arsenic causes oxidative stress and may enhance the activities of antioxidative enzymes such as peroxidase and ascorbic acid. The increased activity may also be compensated by other effects and inhibitions due to arsenic toxicity.

\section{REFERENCES}

[1] T. Roychowdhury, T. Uchino, T. Tokunaga, M. Ando, "Survey of arsenic in food composites from an arsenicaffected area of West Bengal, India", Food Chem. Toxicol., vol. 40, pp. 1611-1621, 2002.

[2] M. G. M. Alam, E. T. Snow, A. Tanaka, "Arsenic and heavy metal contamination in vegetables grown in Samta village, Bangladesh", Sci. Total Environ., vol. 308, pp. 83-96, 2003.

[3] M. R. Islam, M. Jahiruddin, S. Islam, 2004. "Assessment of arsenic in the water-soil-plant systems in gangetic flood plains of Bangladesh", Asian J. Plant Sci., vol. 3, pp. 489-493, 2004.

[4] S. Norra, Z. A. Berner, P. Agarwala, F. Wagner, D. Chandrasekharam, D. Stuben, "Impact of irrigation with As-rich groundwater on soil and crops: a 
geochemical case study in West Bengal delta plain, India”, Appl. Geochem., vol. 20, pp. 1890-1906, 2005.

[5] P. N. Williams, A. H. Price, A. Raab, S. A. Hossain, J. Feldmann, A. A. Meharg, "Variation in arsenic speciation and concentration in paddy rice related to dietary exposure", Environ. Sci. Technol., vol. 39, pp. 5531-5540, 2005.

[6] R. Zhao, M. Zhao, H. Wang, Y. Taneike, X. Zhang, "Arsenic speciation inmoso bamboo shoot - a terrestrial plant that contains organoarsenic species", Sci. Total Environ, vol. 371, pp. 293-303, 2006.

[7] H. A. Rashid, D. K. Nath, M. Hossain, M. U. Khan, M, A. L. Shah, M. A. Saleque, M. S. Rahman, M. A. Ghani, Variation of arsenic content in groundwater with depth and river distance: GIS mapping. In: Latif Shah, et al., (Eds.). Arsenic in the food chain: assessment of arsenic in the water-soil-crop systems. BRRI, Gazipur, Bangladesh, pp. 53-71, 2004.

[8] M. B. Alam, and M. A. Sattar, "Assessment of arsenic contamination in soils and waters in some areas of Bangladesh", Water Sci. Tech, vol. 42, pp. 185-193, 2000.

[9] S. M. Ullah, Arsenic contamination of ground water and irrigated soils of Bangladesh. In Abstracts: International Conference on Arsenic Pollution of Ground Water in Bangladesh: Causes, Effects and Remedies, 8-12 February, Dhaka Community Hospital, Dhaka, Bangladesh. 1998, 133p.

[10] A. A. Meharg, "Arsenic in rice - understanding a new disaster for South-East Asia", Trends in Plant Sci., vol. 9, pp. 415-417, 2004.

[11] K. Ohno, T. Yanase, Y. Matsuo, T. Kimura, M. H. Rahman, Y. Magara, and Y. Matsui, "Arsenic intake via water and food by a population living in an arsenicaffected area of Bangladesh", Sci of the Total Envi., vol. 381, pp. 68-76, 2007.

[12] M. J. Abedin, and A. A. Meharg , "Relative toxicity of arsenite and arsenate on germination and early seedling growth of rice (Oryza sativa L.)", Plant Soil, vol. 243, pp. 57-66, 2002.

[13] M. Shri, S. Kumar, D. Chakrabarty, P. K. Trivedi, S. Mallick, P. Misra, D. Shukla, S. Mishra, S. Srivastava, R. D. Tripathi, and R. Tuli, "Effect of arsenic on growth, oxidative stress, and antioxidant system in rice seedlings", Ecotoxicology and Environmental Safety, vol. 72, pp. 1102-1110, 2009.

[14]H. P. Singh, D. R. Batish, R. K. Kohlo, K. Arora, "Arsenic-induced root growth inhibition in mung bean (Phaseolus aureus Roxb.)is due to oxidative stress resulting from enhanced lipid peroxidation", Plant Growth Regul., vol. 53, pp. 65-73, 2007.

[15]R. Requejo, M. Tena, "Proteome analysis of maize roots reveals that oxidative stress is a main contributing factor to plant arsenic toxicity", Phytochemistry, vol. 66, pp. 1519-1528, 2005.

[16]A. A. Abdul-Baki, and J. D. Anderson , "Vigor determination in soybean seeds by multiple criteria," Crop Sci, vol. 3, pp. 630-3, 1973.

[17]D. I. Arnon, "Copper enzymes in isolated chloroplasts: polyphenol oxidase in Beta vulgaris", Plant Physiology, vol. 24 pp. 1-15, 1949.

[18]S. Sadasivam, and A. Manickam, Biochemical methods for agricultural science, Wiley Eastern Limited and Tamil Nadu Agricultural University, Coimbatore, 1991.

[19] O. H. Lowry, N. J. Rosebrough, A. L. Farr, and R. J. Randall, "Protein measurement with the Folin phenol reagent", The Journal of Biological Chemistry, vol. 193(1), pp. 265-275, 1951.

[20] W. J. Liu, Y. G. Zhu, F. A. Smith, and S. E. Smith, "Do phosphorus nutrition and iron plaque alter arsenate (As) uptake by rice seedlings in hydroponic culture", New Phytololist., vol. 162, pp. 481-488, 2004.

[21]N. Stoeva, and T. Bineva, "Oxidative changes and photosynthesis in oat plants grown in as-contaminated soil", Bulgarian Journal of Plant Physiology, vol. 29, pp. 87-95, 2003.

[22]E. Miteva, and M. Merakchiyska, "Response of chloroplasts and photosynthetic mechanism of bean plants to excess arsenic in soil", Bulg J.Agric Sci., vol. 8, pp. 151-156, 2002.

[23] W. C. Fang, C. Kao, "Enhanced peroxidase activity in rice leaves in response to excess iron, copper and zinc", Plant Sci., vol. 158, pp. 71-76, 2000.

[24] R. K. Tewari, P. Kumar, P. N. Sharma, S. S. Bisht, "Modulation of oxidative stress responsive enzymes by excess cobalt", Plant Science, vol. 162, pp. 381-388, 2002.

[25]F. Zengin, O. Munzuroglu, "Effect of some heavy metals on content of chlorophyll, proline and some antioxidant chemicals in bean (Phaseolus vulgaris L.) seedlings", Acta Biol Crac., vol. 47(2), pp. 157-164, 2005.

[26] N. Pandey, C. P. Sharma, " Effect of heavy metals $\mathrm{Co}^{2+}, \mathrm{Ni}^{2+}$ and $\mathrm{Cd}^{2+}$ on growth an metabolism of Cabbage", Plant Sci., vol. 163, pp. 753-758, 2002.

[27] A. Schützendübel, A. Polle, "Plant responses to abiotic stresses: heavy metal-induced oxidative stress and 
protection by mycorrhization”, J Exp. Bot., vol. 53, pp. 1351-1365, 2002.

[28]D. Gupta et al., "Antioxidant defense mechanism in hydroponically grown Zea mays seedlings under moderate lead stress", J. Hazard. Mater., Vol. 172, pp. 479-484, 2009.

[29]F. Sanal, G. Şeren, U. Güne, "Effects of arsenate and arsenite on germination and some physiological attributes of barley Hordeum vulgare L.”, Bulletin of Environmental Contamination and Toxicology, vol. 92 (4), pp. 483-489, 2014.

[30]R. G. Alscher, J. L. Donahue, and C. L. Cramer, "Reactive oxygen species and antioxidants: Relationship in green cells", Plant Physiology, vol. 100 pp. 224-233, 1997. 